\title{
Determining the optimal construction method for basements using the Analytic Hierarchy Process
}

\author{
Ali Maaruf*, Pavel Oleynik \\ Moscow State University of Civil Engineering, 129377, Moscow, Russia
}

\begin{abstract}
In the construction industry, there are two methods for constructing basements (Top-Down) and (Bottom-UP). The difference between them lies in the sequence of works, since in the (Bottom-Up) method the end of the excavation work is the necessary condition for the beginning of the substructure construction, and this is different from the (Top Down) method where excavation and construction of the substructure and the superstructure are carried out in parallel, which significantly reduces the project duration but at the same time increases the construction cost. Also there is a difference in terms of use for each of these two methods, for example, it is preferable to use the (Top-Down) in dense urban areas, where there is not enough space for the construction and where there are concerns that the adjacent buildings may be deformed as a result of construction, and this is what the (Bottom-Up) method cannot provide. In order to determine the optimal method from a mathematical point of view, 7 main criteria and 25 sub-criteria were identified, and the Analytic Hierarchy Process was used to solve this multi-criteria problem. Using the Expert Choice software, we found that the (Top-Down) method is preferred by $14.8 \%$ more than (Bottom-Up), and a sensitivity analysis was performed to determine which criteria dominated our optimal result.
\end{abstract}

\section{Introduction:}

Construction activities have always had a conventional work sequence and the first task to be done was excavation work. This sequence of work is called (Bottom-Up), in which the substructure and superstructure are performed sequentially from the foundation level to the top of the superstructure, but due to the limitations of buildings height in some cities and other restrictions above the ground such as dense urban areas, investors and landowners are looking for the maximum utilization of the underground space with the shortest construction time to maximize profits. One of the ways to achieve the aforementioned points is the (Top-Down) construction method, which is being used a lot in European cities, Russia, USA, Vietnam, and India. The (Top-Down) method does not require a large working space compared to (Bottom-Up) and such a method allows to reduce construction time due to the simultaneous execution of works [1]. It is defined as the reverse of the (Bottom-Up) method, which removes the excavation works from the critical path of the

\footnotetext{
* Corresponding author: Alimaaruf450@gmail.com
} 
project and breaks the sequence between the end of the excavation works and the start of the substructure, thereby reducing construction time. Both of (Top-Down) and (Bottom-Up) have their advantages and disadvantages, and, for example, if we choose to use one of these methods according to the cost criterion, we will definitely choose (Bottom-Up), because the technical and economic comparison for constructing the substructure of a business center in Moscow showed that the total cost increased by $37.7 \%$ when using (Top-Down) [2], and if the choice will be based on the duration criterion, we will definitely choose (Top-Down), because the comparison of project duration in India showed that the total duration decreased by $26 \%$ when using (Top-Down) method [3].

The problem arises when both criteria must be used simultaneously or when other criteria need to be added, thus the selection becomes more complex and becomes necessary to use mathematical methods to make multi-criteria decision to reach the optimum and most correct solution. One of these methods is the Analytic Hierarchy Process (AHP) developed by Iraqi scientist Thomas L. Saaty.

The Analytic Hierarchy Process (AHP) is a basic approach to decision making. It is designed to cope with both the rational and the intuitive to select the best from a number of alternatives evaluated with respect to several criteria. In this process, the decision-maker carries out simple pairwise comparison judgments, which are then used to develop overall priorities for ranking the alternatives. The AHP both allows for inconsistency in the judgments and provides a means to improve consistency [4].

\section{Materials and Methods:}

\subsection{Key steps of the Analytic hierarchy process:}

The essence of this method is to simplify complex problems and present them in a hierarchical manner, allowing the human mind to make a compare the proposed alternatives. The decision should be divided into steps in order to obtain priorities [5]:

Step1 - We have to define the problem.

Step2 - Structure the decision hierarchy from the top with the goal of the decision, then the objectives from a broad perspective, through the intermediate levels to the lowest level.

Setp3 - Construct a set of pairwise comparison matrices. Each element in an upper level is used to compare the elements in the level immediately below with respect to it. comparisons are made based on "Saaty" scale shown in Table 1, which indicates how many times an element is more important than another with respect to the criterion or property to which they are compared.

Setp4 - Use the priorities obtained from the comparisons to weigh the priorities in the level immediately below. We continue this process of weighing and adding until the final priorities of the alternatives are obtained at the lowest level.

Table 1. The Scale of Saaty

\begin{tabular}{|c|l|l|}
\hline $\begin{array}{c}\text { Intensity of } \\
\text { Importance }\end{array}$ & \multicolumn{1}{|c|}{ Definition } & \multicolumn{1}{c|}{ Explanation } \\
\hline $\mathbf{1}$ & Equal Importance & $\begin{array}{l}\text { Two activities contribute equally to the } \\
\text { objective }\end{array}$ \\
\hline $\mathbf{2}$ & Weak or slight & $\begin{array}{l}\text { Experience and judgement slightly favor } \\
\text { one activity over another }\end{array}$ \\
\hline $\mathbf{3}$ & Moderate importance & $\begin{array}{l}\text { Experience and judgement strongly favor } \\
\text { one activity over another }\end{array}$ \\
\hline $\mathbf{4}$ & Moderate plus & Strong importance \\
\hline $\mathbf{5}$ &
\end{tabular}




\begin{tabular}{|c|c|c|}
\hline 6 & Strong plus & \\
\hline 7 & $\begin{array}{l}\text { Very strong or } \\
\text { demonstrated importance }\end{array}$ & $\begin{array}{l}\text { An activity is favored very strongly over } \\
\text { another; its dominance demonstrated in } \\
\text { practice }\end{array}$ \\
\hline 8 & Very, very strong & \\
\hline 9 & Extreme importance & $\begin{array}{l}\text { The evidence favoring one activity over } \\
\text { another is of the highest possible order of } \\
\text { affirmation }\end{array}$ \\
\hline $1.1 \sim 1.9$ & $\begin{array}{l}\text { If the activities are very } \\
\text { close }\end{array}$ & $\begin{array}{l}\text { May be difficult to assign the best value but } \\
\text { when compared with other contrasting } \\
\text { activities the size of the small numbers } \\
\text { would not be too noticeable, yet they can } \\
\text { still indicate the relative importance of the } \\
\text { activities. }\end{array}$ \\
\hline
\end{tabular}

\subsection{Sensitivity analysis:}

Sensitivity analysis is the study of how the uncertainty in the output of a mathematical model or system (numerical or otherwise) can be divided and allocated to different sources of uncertainty in its inputs [6]. Thus, a sensitivity analysis is needed to show how decision might change when the relative importance of criteria changes when solving a multi-criteria problem.

\subsection{Modeling the problem in the Expert choice software:}

In this article, Expert Choice (EC) software has been used to model the problem we encountered due to the efficiency that this software provides when solving pairwise comparison matrices and determining the priorities of all criteria. It also allows us to constantly determine the percentage of inconsistency, which should not exceed $10 \%$, so that our judgments do not seem chaotic. In addition to the above, the software gives a reliable final solution by performing a sensitivity analysis that ensures that our preferences entered into the matrices are unbiased.

\subsubsection{The problem and the goal:}

The problem is expressed in the complexity of the choice between the two proposed alternatives, as it depends on a large number of criteria, and thus the goal is to determine the optimal alternative with respect to all criteria together.

\subsubsection{The set of criteria that dominates the problem:}

The choice of basement construction method depends on many different criteria, some criteria are more important and dominate others, for example (duration criterion) or (geotechnical criterion) could be more important than (Organizational and technical criterion). Based on the literature review, and questioning of experts the advantages and disadvantages of each method were gathered, and we concluded that when choosing the optimal method, the following set of criteria should be taken into account:

Table 2. The set of criteria for determining the optimal method.

\begin{tabular}{|c|c|c|}
\hline Economic criterion & 2. Duration criterion & Risk criterion \\
\hline $\begin{array}{l}\text { 1.1. Design cost } \\
\text { 1.2. } \text { Construction cost }\end{array}$ & $\begin{array}{l}\text { 2.1. Duration of the design } \\
\text { phase }\end{array}$ & $\begin{array}{l}\text { 3.1. Risk associated } \\
\text { with failure of the }\end{array}$ \\
\hline
\end{tabular}




\begin{tabular}{|c|c|c|c|}
\hline & $\begin{array}{ll}\text { 1.2.1. } & \text { Labor cost } \\
\text { 1.2.2. } & \text { Equipment cost } \\
1.2 .3 . & \text { Material cost } \\
\text { Reducing additional indirect } \\
\text { cost resulting from work } \\
\text { interruption due to bad } \\
\text { weather } \\
\begin{array}{l}\text { Benefits gained from fast } \\
\text { completion } \\
\text { commissioning. }\end{array}\end{array}$ & $\begin{array}{l}\text { 2.2. Duration of the } \\
\text { construction phase. }\end{array}$ & $\begin{array}{l}\text { design process. } \\
\text { 3.2. Risk associated } \\
\text { with failure of the } \\
\text { entire project. } \\
\text { 3.3. Risk that threaten } \\
\text { the workers. } \\
\text { 3.4. Financial risk } \\
\text { resulting from } \\
\text { exceeding the } \\
\text { contract value. } \\
\text { 3.5. Risk associated } \\
\text { with the safety of } \\
\text { adjacent buildings. } \\
\text { 3.6. Risk associated } \\
\text { with the duration of } \\
\text { the contract. }\end{array}$ \\
\hline & $\begin{array}{l}\text { Possibility of a decrease in } \\
\text { the quality of works. }\end{array}$ & $\begin{array}{lll}5 . & \begin{array}{l}\text { Organizational } \\
\text { technical criterion }\end{array} & \text { and } \\
\end{array}$ & $\begin{array}{ll}6 . & \text { Geotechnical } \\
\text { criterion }\end{array}$ \\
\hline & & $\begin{array}{l}\text { 5.1. Possibility of carrying out } \\
\text { works in confined spaces } \\
\text { and small construction } \\
\text { sites. } \\
\text { 5.2. Complexity of the } \\
\text { organizational process of } \\
\text { workers at the construction } \\
\text { site. } \\
\text { 5.3. Complexity of project } \\
\text { management. } \\
\text { 5.4. Possibility for productivity } \\
\text { to be affected by working } \\
\text { conditions. } \\
\text { 5.5. Possibility of using a } \\
\text { tower crane to work in the } \\
\text { substructure } \\
\text { superstructure. }\end{array}$ & $\begin{array}{l}\text { 6.1. Possibility of } \\
\text { implementing the project } \\
\text { in the presence of a large } \\
\text { amount of groundwater. } \\
6.2 \text {. Possibility to reduce } \\
\text { deformation of basement } \\
\text { walls and adjacent } \\
\text { buildings. } \\
6.3 \text {. Possibility of } \\
\text { constructing basements } \\
\text { with a depth of more than } \\
15 \text { meters. }\end{array}$ \\
\hline \multicolumn{4}{|c|}{ 7. $\quad$ Experience criterion } \\
\hline
\end{tabular}

\subsubsection{Discussion of the proposed criteria:}

- In the Economic criterion:

The design cost, which is preferred to be minimized, is higher in the case of the (Top-Down) method because of the additional design considerations and a different design methodology [7].

The labor cost, which is preferred to be minimized, is slightly higher in the case of the (Top-Down) method because of the working conditions in a closed space under the floor slabs [2].

$>$ The equipment cost, which is preferred to be minimized, is slightly higher in the case of the (Top-Down) method because of the special equipment used.

$>\quad$ The materials cost, which includes the cost of additional support and the cost of temporary lighting and ventilation systems. This cost in the case of the (Top-Down) method is lower, due to the need to install additional supports and formwork for slabs in the case of (Bottom-Up) method [7]. 
Indirect cost due to the forced interruption in work, which is preferred to be minimized, is lower in the case of the (Top-Down) method due to the fact that the works can be carried out in closed spaces that are not affected by the weather [7].

$>$ Benefits from project commissioning, which are preferred to be maximized, are greater in the case of (Top-Down) due to the shortened project duration.

○ In the Duration criterion:

$>$ The duration of the design process, which is preferred to be minimized, is shorter in the case of (Bottom-Up) method because of the traditional design methodology.

$>$ The duration of the construction phase, which is preferred to be minimized, is shorter in the case of the (Top-Down) method due to the parallel execution of the substructure and superstructure, which shortens the overall construction period [3].

- In the Risk criterion:

$>$ The risk associated with the failure of the design process, which is preferred to be minimized, is higher in the case of the (Top-Down) method because of the differences in design methodology and lack of information about this method.

The risk associated with the failure of the entire project, which is preferred to be minimized, is higher in the case of the (Top-Down) method because of the insufficient experience and the complexity of working conditions under the slabs.

$>$ The risk that threatens the workers is higher in the case of the (Top-Down) method because of the special conditions in which the works are carried out.

$>$ Financial risk in the case of the (Top-Down) method is higher because of the possibility of unforeseen problems during the execution of works under slabs.

$>\quad$ The risk associated with the safety of adjacent buildings is higher in the case of the (Bottom-Up) method because of the large deformations of the soil $[8,9]$.

$>\quad$ The risk associated with the duration of the contract is higher in the case of the (Top-Down) method because of the possibility of unforeseen problems during the execution of works under slabs.

- In the quality criterion, which is preferred to be maximized, the probability of a deviation in the quality of the performed work is higher in the case of the (Top-Down) method because of the special conditions that control the construction site.

- In the organizational and technical criterion:

$>$ The possibility of carrying out works in confined spaces and small construction sites, which is preferred to be maximized, is higher in the case of the (Top-Down) method due to the possibility of using the ground floor slab as a temporary working platform $[1,7]$.

$>\quad$ The complexity of the organizational process of workers at the construction site, which is preferred to be minimized, is higher in the case of the (Top-Down) method because of the limited space under the slabs [10].

$>$ The complexity of project management, which is preferred to be minimized, is higher in the case of the (Top-Down) method because of the large intersection between tasks and parallelism in execution.

The possibility for productivity to be affected by working conditions, which is preferred to be minimized, is higher in the case of the (Top-Down) method because of the limited working space and special conditions in which the works are carried out.

$>$ The possibility of using a tower crane to work in the substructure and superstructure, which is preferred to be maximized, is higher in the case of the (Top-Down) method due to the possibility of installing the crane on the superstructure from the beginning.

○ In the geotechnical criterion:

$>$ The possibility of implementing the project in the presence of a large amount of groundwater, which is preferred to be maximized, is higher in the case of the (Top-Down) 
method, due to the impermeability of the diaphragm wall and the rigidity of the slabs that support the wall to resist the high pressure of groundwater [11,12].

$>$ The possibility to reduce the deformation of basement walls and adjacent buildings, which is preferred to be maximized, is higher in the case of the (Top-Down) method due to the high rigidity of the slabs that support the basement walls $[8,9]$.

The possibility of constructing basements with a depth of more than 15 meters, which is preferred to be maximized, is higher in the case of the (Top-Down) method due to the high rigidity of the slabs and additional support elements that resist the high pressure of the soil.

$\circ$ In the experience criterion:

$>$ The need for a highly qualified and specialized contractor, which is preferred to be minimized to minimize the contractor's wages, is much higher in the case of the (TopDown) method because of the peculiarities and complexity of this method [10].

The need for a highly qualified and specialized design organization, which is preferred to be minimized to minimize the design organization's wages, is much higher in the case of the (Top-Down) method because of the peculiarities and complexity of this method [10].

\subsubsection{Comparing the relative importance:}

The number of pairwise comparison matrices when comparing the relative importance reached 8 and 25 when comparing the relative preference and in all matrices it was taken into account that the inconsistency coefficient must not exceed $10 \%$ as mentioned above. The red values in the matrices in the following figures indicate that criteria in columns are preferred over criteria in rows.

\begin{tabular}{|c|c|c|c|c|c|c|c|}
\hline \multicolumn{8}{|c|}{ Compare the relative importance with respect to: Goal: Determining the optimal construction method for basements (G) } \\
\hline & Economic criteria (C1) & Duration criterion (C2) & Risk criterion (C3) & Quality crit & Organizatic & Geotechnic & Experience \\
\hline Economic criteria (C1) & & 5.0 & 2.0 & 2.0 & 3.0 & 3.0 & 4.0 \\
\hline Duration criterion (C2) & & & 4.0 & 6.0 & 7.0 & 3.0 & 2.0 \\
\hline Risk criterion (C3) & & & & 3.0 & 4.0 & 2.0 & 3.0 \\
\hline Quality criterion (C4) & & & & & 2.0 & 4.0 & 5.0 \\
\hline Organizational and technical criterion (C5) & & & & & & 5.0 & 6.0 \\
\hline Geotechnical criterion (C6) & & & & & & & 2.0 \\
\hline Experience criterion (C7) & Incon: 0.02 & & & & & & \\
\hline
\end{tabular}

Fig. 1. Comparing the relative importance of criteria with respect to goal.

Compare the relative importance with respect to: Risk criterion (C3)

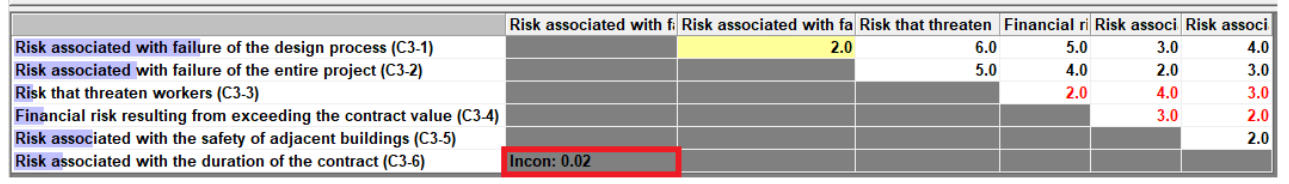

Fig. 2. Comparing the relative importance of risk sub-criteria with respect to risk criterion.

Compare the relative importance with respect to: Geotechnical criterion (C6)

\begin{tabular}{|c|c|c|c|}
\hline & Possibility of impleme & Possibility to reduce dt & Possibility of const \\
\hline Possibility of implementing the project in the presence of a large amount of groundwater (C6-1) & & 2.0 & 3.0 \\
\hline Possibility to reduce deformation of basement walls and adjacent buildings.(C6-2) & & & 2.0 \\
\hline Possibility of constructing basements with a depth of more than 15 meters. (C6-3) & Incon: 0.01 & & \\
\hline
\end{tabular}

Fig. 3. Comparing the relative importance of geotechnical sub-criteria with respect to geotechnical criterion. 
Compare the relative preference with respect to: Economic criteria (C1) I design cost (C1-1)

\begin{tabular}{l|l|r|}
\hline \hline & Top-Down method & Bottom-Up method \\
\hline $\begin{array}{l}\text { Top-Down method } \\
\text { Bottom-Up method }\end{array}$ & Incon: 0.00 & \\
\hline
\end{tabular}

Fig. 4. Comparing the relative preferences of alternatives with respect to design cost.

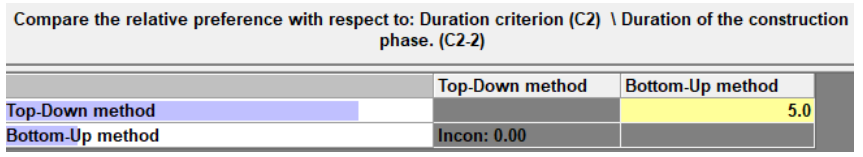

Fig. 5. Comparing the relative preferences of alternatives with respect to the duration of the construction phase.

\begin{tabular}{|c|c|c|}
\hline & Top-Down method & Bottom-Up method \\
\hline Top-Down method & & 3.0 \\
\hline Bottom-Up method & Incon: 0.00 & \\
\hline
\end{tabular}

Fig. 6. Comparing the relative preferences of alternatives with respect to risk that threaten workers.

\begin{tabular}{|c|c|c|}
\hline \multicolumn{3}{|c|}{$\begin{array}{l}\text { Compare the relative preference with respect to: Geotechnical criterion (C6) I Possibility of } \\
\text { constructing basements with a depth of more than } 15 \text { meters. (C6-3) }\end{array}$} \\
\hline & Top-Down method & Bottom-Up method \\
\hline Top-Down method & & 5.0 \\
\hline Bottom-Up method & Incon: 0.00 & \\
\hline
\end{tabular}

Fig. 7. Comparing the relative preferences of alternatives with respect to possibility of constructing basements with a depth of more than 15 meters.

\section{Results:}

\subsection{Calculating the priorities (weights):}

After entering all the matrices, the software calculated all priorities with respect to goal and to each criterion separately, and in the end of this process, the optimal result was determined.

\begin{tabular}{|l|l|}
\hline \multicolumn{1}{|c|}{ Priorities with respect to: } \\
Goal: Determining the optimal construction method for basements (.. \\
Duration criterion (C2) \\
Experience criterion (C7) \\
Geotechnical criterion (C6) & .354 \\
Risk criterion (C3) & .240 \\
Economic criteria (C1) & .159 \\
Quality criterion (C4) & .104 \\
Organizational and technical criterion (C5) & .068 \\
Inconsistency = 0.02 & .031 \\
with 0 missing judgments.
\end{tabular}

Fig. 8. Priorities of criteria with respect to the goal. 


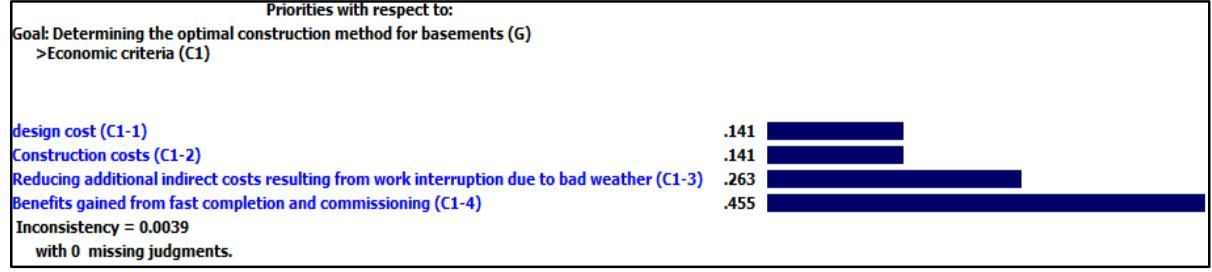

Fig. 9. Priorities of economic sub-criterion with respect to economic criterion.

\begin{tabular}{|l|}
\hline \multicolumn{1}{|c|}{ Priorities with respect to: } \\
$\begin{array}{l}\text { Goal: Determining the optimal construction method for basements (G) } \\
\text { >Economic criteria (C1) } \\
>\text { design cost (C1-1) }\end{array}$ \\
$\begin{array}{l}\text { Top-Down method } \\
\text { Bottom-Up method } \\
\text { Inconsistency }=0 \text {. } \\
\text { with } 0 \text { missing judgments. }\end{array}$ \\
\hline
\end{tabular}

Fig. 10. Priorities of design cost sub-criterion with respect to alternatives.

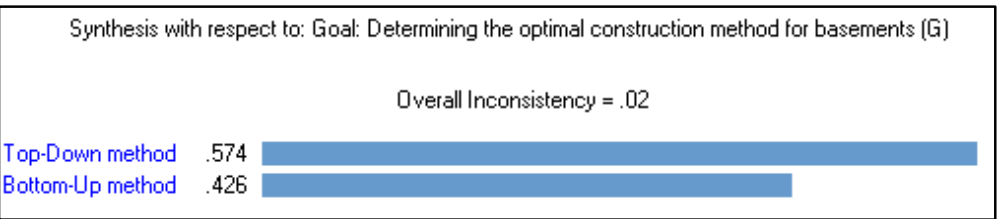

Fig.11.Synthesis with respect to goal.

In Figure 11, we noticed that the (Top-Down) method scored the highest rate 57.4\%, so it is considered the best and optimal compared to (Bottom-Up). However, it was necessary to conduct a sensitivity analysis to determine the criteria that dominate the result, so that these criteria are given more attention when determining their priorities, since any change in their priorities will significantly affect the result. 


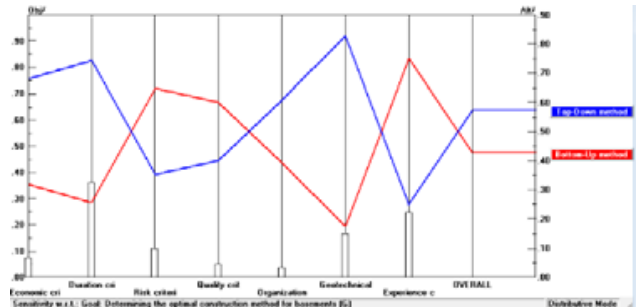

Fig. 12. Result before sensitivity analysis.

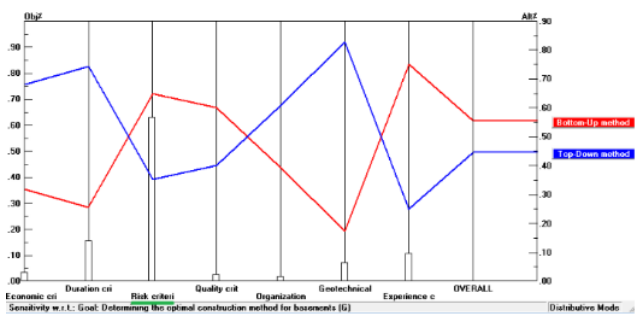

Fig. 14. Result sensitivity to risk criterion.

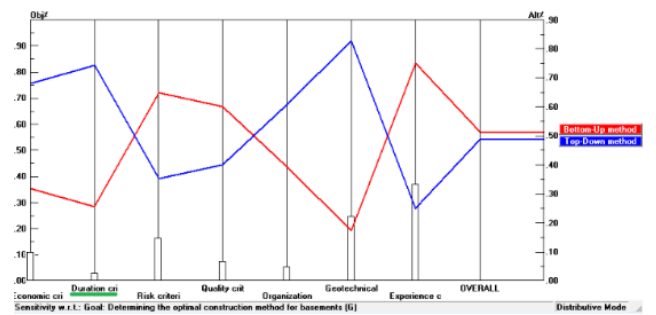

Fig. 13. Result sensitivity to duration criterion.

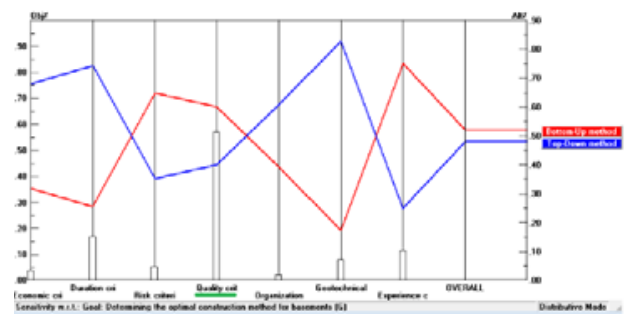

Fig. 15. Result sensitivity to duration criterion.

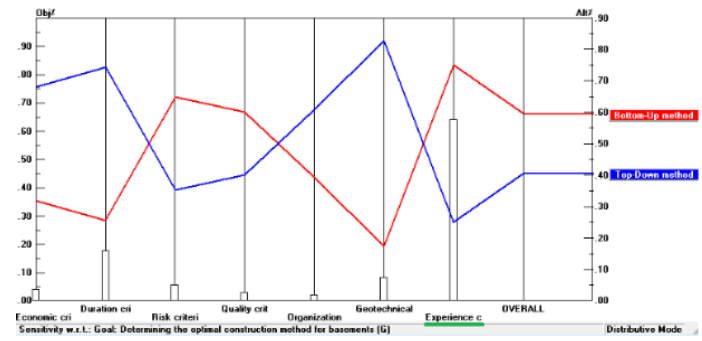

Figure 16. Result sensitivity to experience criterion.

\section{Discussion:}

There is no doubt that adopting one of the (Top-Down) or (Bottom-Up) methods for basements construction by relying on one criterion only would have led to bias and unscientific choice based on purely personal judgment, and thus choosing the not optimal alternative with which it creates a lot of problems that exhaust the project. If we compared the aforementioned alternatives by benefit-to-cost method, then only the optimal alternative from an economic point of view would be chosen regardless the other aspects, and this is not desirable in the modern world that seeks the most optimal. The literature review and experts opinion in the basements construction field allowed us to define the set of criteria that ensure the optimal choice between the two proposed alternatives, and the Analytic Hierarchy Process determined the optimal alternative in this multi-criteria problem by giving preferential judgments that are monitored mathematically. Expert choice software helped us in calculating the priorities and conducting a sensitivity analysis of the result, and we found that: 
- If the priority of duration criterion was reduced by $30 \%$ (meaning that we no longer prefer to shorten the construction phase), then the optimal alternative will be (Bottom-Up) method as shown in figure 13.

- If the priority of risk criterion was increased by $40 \%$ (meaning that we prefer to work at the lowest level of risk), then the optimal alternative will be (Bottom-Up) method as shown in figure 14 .

- If the priority of quality criterion was increased by $45 \%$ (meaning that we prefer to have the highest level of quality) then the optimal alternative will be (Bottom-Up) method as shown in figure 15.

- If the priority of experience criterion was increased by $45 \%$ (meaning that we prefer the contractors and designers with small experience who accept low wages) then the optimal alternative will be (Bottom-Up) method as shown in figure 16.

\section{Conclusions:}

The preferential ratios for each method are shown in figure (11), and the difference between these ratios does not exceed (14.8\%). Obviously, it is not an absolute preference, this is because it was taken into account not to make absolute preference judgments in the pairwise comparison matrices step to prevent any bias in the result, accordingly, we recommend adopting the (Top-Down) method in basements construction if the required criteria meet the criteria mentioned in this research paper. We also recommend the use of artificial intelligence (expert systems) that would help solve this complex problem by reasoning through bodies of knowledge, represented mainly as if-then rules.

\section{References:}

1. S.S. Basarkar, M. Kumar, B.G. Mohapatro, and P.R. Mutgi, Emerging Trend in Deep Basement Construction: Top-Down Technique, IOSR Journal of Mechanical and Civil Engineering (IOSR-JMCE), 1-11. ISSN: 2278-1684.

2. A.A. Goncharov, Choosing the method of construction of the underground part of the building, Promyshlennoe i Grazhdanskoe Stroitelstvo 5, 57-61 (2020) doi: 10.33622/0869-7019.

3. R. Sakharkar, Comparative Study of Top down \& Bottom up Method Construction Schedule with Respect to Construction of a Residential Building, International Research Journal of Engineering and Technology (IRJET) 06(02), 2233-2237 (2019) e-ISSN: 2395-0056.

4. Thomas L. Saaty, Luis G. Vargas, Models, Methods, Concepts \& Applications of the Analytic Hierarchy Process, Springer, New York, USA (2012) doi: 10.1007/978-14614-3597-6.

5. Thomas L. Saaty, Decision making with the analytic hierarchy process, Int. J. Services Sciences, Pittsburgh, USA. 1(1), 83-97 (2008)

6. A Saltelli, Sensitivity Analysis for Importance Assessment, Risk Analysis 22(3), 1-12 (2002) doi: 10.1111/0272-4332.00040.

7. John Endicott, Digging deeper and smarter https://aecom.com/withoutlimits/article/digging-deeper-smarter/.

8. J.H. Wang, Z.H. Xu, and W.D. Wang, Wall and ground movements due to deep excavations in Shanghai soft soils, Journal of Geotechnical and Geoenvironmental Engineering 136(7), (2010). 10.1061/(ASCE)GT.1943-5606.0000299, P.985-994. 
9. Z. H. Xu, Deformation behavior of deep excavations supported by permanent structures in Shanghai soft deposit (Ph.D. thesis, Shanghai Jiao Tong Univ., Shanghai, China, 2007).

10. R. Katzenbach, R.A. Dunaevsky, A.A. Franivsky, Top-down construction method http://www.yaros.by/library/professionalnaya-informatsiya/metod-stroitelstva-sverhuvniz.html.

11. V.K. Paul, S. Khursheed and R. Singh, Comparative Study of Construction Technologies for Underground Metro Stations in India, Int. J. Res. Eng. Technol. 06(03), 55-63 (2017) doi: 10.15623/ijret.2017.0603009.

12. J.Y. Wong, C.C. Yip, K.L. Mugumya, B.H. Tan and M.P. Anwar, Effectiveness of Top-down Construction Method in Malaysia, International Journal of Innovative Technology and Exploring Engineering 8 Issue-6S4, 386-392 (2019) doi: 10.35940/ijitee.F1078.0486S419. 